American Journal of Nanotechnology 1 (2): 56-61, 2010

ISSN 1949-0216

(C) 2010 Science Publications

\title{
Study on Contact Forms in Wafer Chemical Mechanical Polishing in Nanomachining
}

\author{
${ }^{1} \mathrm{Su}$ Jianxiu, ${ }^{1}$ Du Jiaxi, ${ }^{1}$ Chen Xiqu and ${ }^{2}$ Kang Renke \\ ${ }^{1}$ Henan Institute of Science and Technology, Xinxiang, 453003, PR China \\ ${ }^{2}$ Key Laboratory for Precision and Non-Traditional Machining Technology of Ministry of Education, \\ Dalian University of Technology, Dalian, 116024, PR China
}

\begin{abstract}
Chemical Mechanical Polishing (CMP) has become the most widely used planarization technology in the semiconductor manufacturing process. Problem statement: Studying the Contact Forms in Wafer Chemical Mechanical Polishing. Approach: A series test on the abrasion behavior and the lubricating behavior was conducted and then the test results were investigated by the abrasion and lubrication theory. Results: By the test results and analysis, it showed that the Material Removal Rate (MRR) was mainly due to the interaction between abrasives and polishing slurry and the main material removal of wafer surfaces was two bodies abrasive wear under chemical interaction. By the Stribeck curves obtained, the lubrication state in CMP interface is belong to the boundary lubrication and the material removal is the process of bringing and removed of the chemical reaction boundary lubricating film on wafer surface constantly. Conclusion: By the analysis results, it was concluded that the contact form between the Wafer and the polishing pad is the solid-solid contact. These results will provide theoretical guide to further understand the material removal mechanism of in wafer CMP.
\end{abstract}

Key words: Chemical Mechanical Polishing (CMP), material removal rate, abrasion behavior, lubricating behavior, contact form, boundary lubrication, planarization technology, semiconductor manufacturing process, CMP process, dry friction

\section{INTRODUCTION}

Chemical Mechanical Polishing (CMP) belong to the nanomachining in the semiconductor manufacturing process. Nowadays, it has become the most widely used planarization technology in the manufacturing process of Ultra Large Scale Integrated circuits (ULSI) (Abdullah et al., 2009; Terrell et al., 2010). However, the CMP mechanism has not been understood completely. The present CMP technology is incapable of meeting the needs of wafer surface quality in next generation IC. Studying on the material removal mechanism becomes an important fundamental research work to improve the CMP technology (Bais and Majlis, 2008). Then the material removal mechanism mainly depends on the contact relationships between the wafer and the pad. Because the models built for studying the material removal mechanism of wafer CMP have strong relationships to contact form. Before studying the material removal mechanism deeply, the contact mechanism between the wafer and the pad in wafer CMP process must be understood firstly (Ali et al., 2010).

A schematic of CMP system sees literature (Krishnan et al., 2010). In the CMP process, a rotating wafer is pressed face down onto a rotating polishing pad at a proper pressure. The polishing slurry containing submicron or nanometer abrasives and chemical reagents flows between the wafer and the pad. The chemical reactant film is formed on wafer surface and then the reactant is removed from wafer surface by the mechanical action. The new surface will emerge and the next CMP cycle begins. What is the contact form between the wafer and the pad in wafer CMP process? Some researchers (Bozkaya and Muftu, 2009; Zhao and Chang, 2002; Liang, 2005) considered the contact form between the wafer and the pad is solidsolid contact and the lubrication forms between the wafer and the pad is the boundary lubrication. Some researchers considered that the wafer is not contact with the pad, the hydrodynamic of slurry between the wafer and the pad can float the wafer, the lubrication forms between the wafer and the pad is the hydrodynamic lubrication and the cutting action produced by slurry on wafer surface is the main power in material removal (Yeruva et al., 2009). Some researchers considered that the wafer is semi-contact with the pad, the lubrication forms between the wafer and the pad is mixed lubrication and the polishing pressure on wafer is born by the mutual action of the pad and the slurry ( $\mathrm{Ng}$ et al., 2005).

Corresponding Author: Su Jianxiu, Henan Institute of Science and Technology, Xinxiang 453003, P.R. China Fax: +86-373-3693192 
In wafer CMP process, the movement relationship between the Wafer and the polishing pad exists and the slurry with abrasives can be brought into the polishing region between the wafer and the pad continuously. So the friction phenomena between the wafer and the slurry including abrasives, between the wafer and the pad and between the pad and the slurry can be produced in wafer CMP process (Qura'n, 2007).

So the CMP system composed of the wafer, the slurry and the pad is not only a mechanical system of the mutual movement, is also a tribological system with the friction between the various element. There are the friction, the abrasion and the lubrication phenomena. Therefore, the contact mechanism between the wafer and the polishing pad can be judged from the tribological (lubricating) behavior of the wafer surface materials and the material removal (or abrasion) behavior on the wafer surface. In studying the wafer CMP Theory and Technology, The major goals are how to improve and control Material Removal Rate (MRR) of the wafer surface, that is, the wear rate of wafer surface. The contact state are closely related to the abrasion form and the lubrication form, therefore, so long as the abrasion form of the wafer surface materials and the lubrication form between the wafer and the pad have been found out, then, the contact form between the wafer and the pad can be further obtained.

\section{Analysis of the lubrication behavior in the wafer CMP process:}

The discrimination of the lubrication form in wafer CMP process: According to lubrication theory, the lubrication form can be divided into 5 types. One is the hydrodynamic lubrication and the thickness of the typical lubrication film is $1-100 \mu \mathrm{m}$. Two is the static pressure lubrication and the thickness of the typical lubrication film is $1-100 \mu \mathrm{m}$. Three is the flexibility hydrodynamic lubrication and the thickness of the typical lubrication film is $0.1-1 \mu \mathrm{m}$. Four is the thin film lubrication and the thickness of the typical lubrication film is $10-100 \mathrm{~nm}$. Five is the boundary lubrication and the thickness of the typical lubrication film is $1-50 \mathrm{~nm}$. The last one is the dry friction and the thickness of the typical lubrication film is $1-10 \mathrm{~nm}$. Figure 1 shows the friction coefficient at the various lubrication conditions. Figure 2 is a typical lubrication curve of the lubrication state transformation, this is the well-known Stribeck curve. It can very clearly reflect the variation relationship of the lubrication state and the motion parameters.

According to above mentioned, in the wafer CMP process, as long as the friction coefficient between the wafer and the pad can be known, the lubrication state can be determined. The friction coefficient is very easy to measure on-line in the wafer CMP process. Many companies have already produced experimental or commercial CMP machine with detecting the friction coefficient on-line, such as the CP-4 experimental polishing machine produced by the CETR company USA. It is capable of meeting the on-line testing of friction coefficient in wafer CMP process.

\section{MATERIALS AND METHODS}

Experimental equipment and experimental conditions: The CMP tests were conducted on CP-4 CMP machine made by CETR Inc. All the experiments are done in clean room with 1000 grade at the constant temperature of $22^{\circ} \mathrm{C}$. The silicon wafers of 2 inches in diameter, lapped before CMP, are used in polishing experiments. The surface roughness $\mathrm{Ra}$ of the silicon wafer, measured in ZYGO5022 surface profiler, is about $40 \mathrm{~nm}$. DI (deionized) water with the resistance $18.24 \mathrm{M} \Omega \cdot \mathrm{cm}$ is used in CMP test. The Rodel IC1000/Sub IV pad is applied and conditioned with the diamond conditioner online during CMP. It is also conditioned for 15 min using DI water before every polishing. The slurry SS12, made by Cabot Microelectronics Corporation, is used in CMP test.

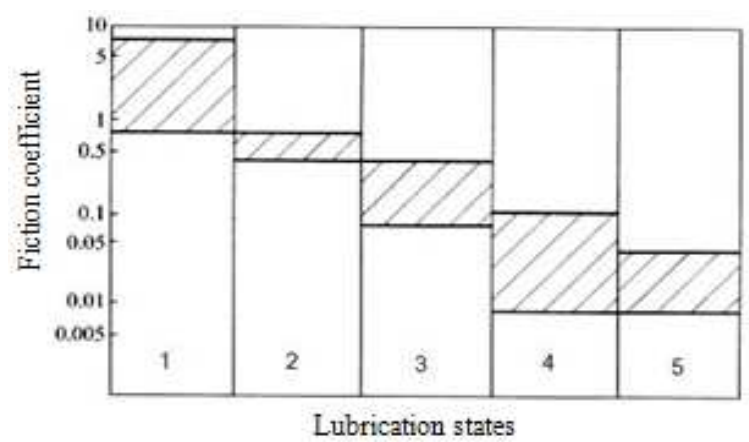

(a)

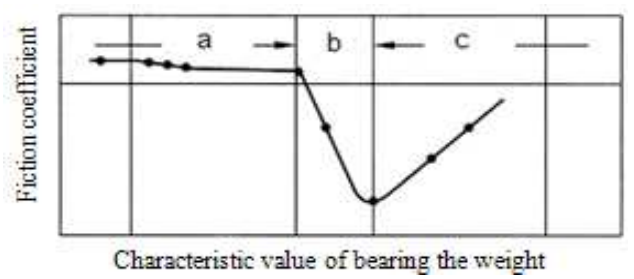

(b)

Fig. 1: The relationship between the lubrication states and friction coefficient and Curve of Stribeck (a) The relationship between the lubrication states and friction coefficient, (b) Curve of Stribeck; (1) The dry friction (metal); (2) The dry friction (oxidation film), (3) the boundary lubrication; (4) The mixed lubrication; (5) The hydrodynamic lubrication; (a) The boundary lubrication; (b) The mixed lubrication, c- The hydrodynamic lubrication 


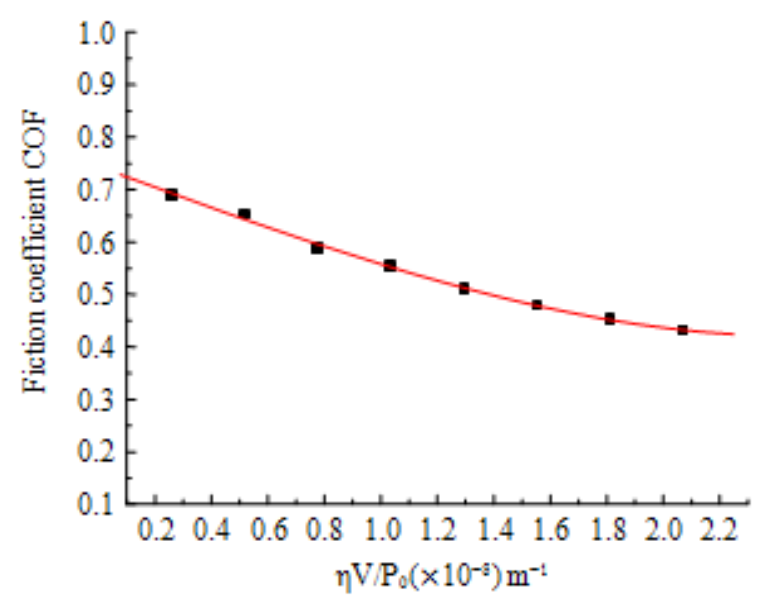

Fig. 2: The "Stribeck curve" of wafer CMP at $\mathrm{p}_{0}=6 \mathrm{psi}$

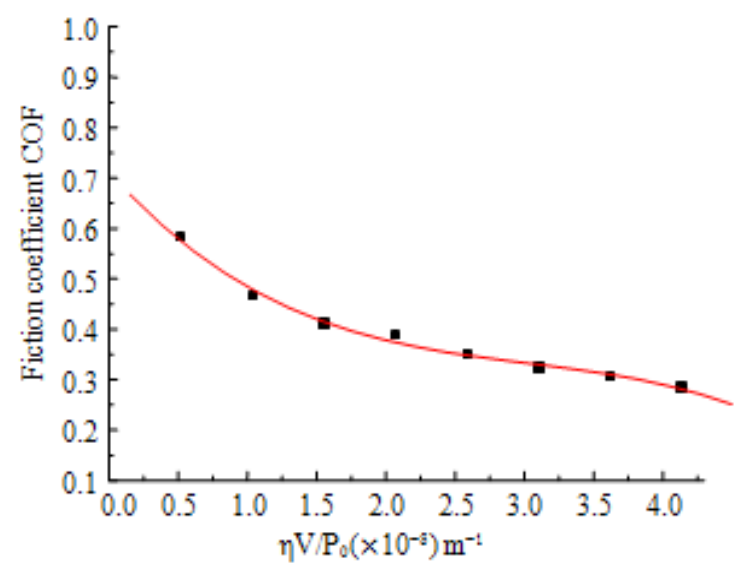

Fig. 3: The "Stribeck curve" of wafer CMP at $\mathrm{p} 0=3 \mathrm{psi}$

Experimental parameters: In the experiments, the down force on the wafer are 3 psi and 6 psi, the carrier has a reciprocating motion with a stroke of $10 \mathrm{~mm}$ at speed of $2.5 \mathrm{~mm} \mathrm{sec}{ }^{-1}$ and the center distance between the platen and the wafer is set $60 \mathrm{~mm}$. The slurry is supplied at the flow rate of $100 \mathrm{~mL} \mathrm{~min}{ }^{-1}$ during the CMP. Each polishing time was $5 \mathrm{~min}$. The rotational speed of polishing head $\mathrm{n}_{\mathrm{w}}$ and the rotational speed of platen $\mathrm{n}_{\mathrm{p}}$ are taken as $\mathrm{n}_{\mathrm{w}}=\mathrm{n}_{\mathrm{p}}=50,100,150,200,250$, $300,350,400 \mathrm{r} \mathrm{min}^{-1}$ in experiments. The friction coefficients of each test are measured online. All the tests repeated three times and each test result took the average value of the three tests.

\section{RESULTS}

In order to evaluate the lubrication behavior in wafer CMP process, the friction coefficients were obtained with the equal rotational speed $\mathrm{n}_{\mathrm{w}}$ and $\mathrm{n}_{\mathrm{p}}$ at the polishing pressure $\mathrm{p}_{0} 3 \mathrm{psi}, 6 \mathrm{psi}$, respectively. The Stribeck curves are shown in Fig. 2-3.

Discrimination of the lubrication state in wafer CMP: In tribology, the friction coefficient is an important parameter to distinguish the lubrication state. By Fig. 2-3, when the $n_{p}=n_{w}=400 r \min ^{-1}$, the maximum line speed on the wafer surface is about 2.5 $\mathrm{m} \mathrm{sec}^{-1}$ and the friction coefficient of polishing system is greater than 0.1. While in the actual CMP process, the polishing speed is about $1 \mathrm{~m} \mathrm{sec}^{-1}$ or less. Comparing with Fig. 1a, the lubrication form in the wafer CMP should be the boundary lubrication, not mixed lubrication. Comparing the Stribeck curve shown in Fig. 2-3 with Fig. 1b, the lubrication state also is boundary lubrication. So, according to the friction characteristics of wafer CMP, it is can be considered that the lubrication is boundary lubrication in the wafer CMP process.

Analysis of the abrasion behavior in wafer CMP process (Su et al., 2008a; 2008b):

The differentiating method of contact form between the wafer and the pad based on abrasion behavior: In wafer CMP process, the abrasion always occurs with friction. So, the contact form can be judged by abrasion kind obtained by the relating test. In wafer CMP process, the film of chemical reaction on wafer surface is removed by mechanical action, but the mechanical action on wafer surface are mainly produced by the abrasive in slurry, the pad and the slurry. Each mechanical action is corresponding to a certain contact state and brings different abrasion behavior. Which one of the mechanical actions plays the dominant role in material removal of wafer CMP process? If the mechanical action form is achieved, the contact form between the wafer and the pad can be obtained.

According to the literature (Lin et al., 2004), the hydrodynamic of slurry between the wafer and the pad can be neglected in wafer CMP process. It is concluded that the higher MRR is obtained when the contact form between the wafer and the pad is solid-solid contact and the lower MRR happens when the wafer does not contact with the pad in wafer CMP process. So at the same condition, when the material removal related to abrasive abrasion is in domination, the contact form between the wafer and the pad can be thought as solidsolid contact. 


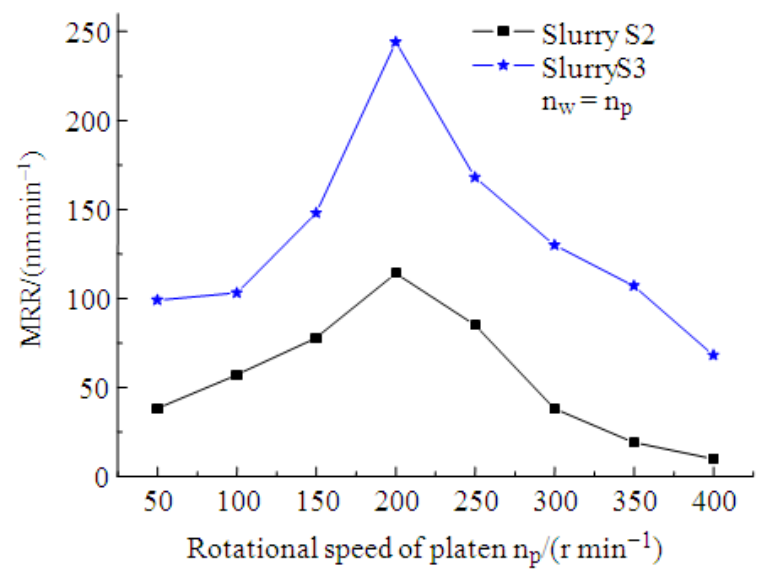

Fig. 4: MRR of CMP using slurry S2 and slurry S3

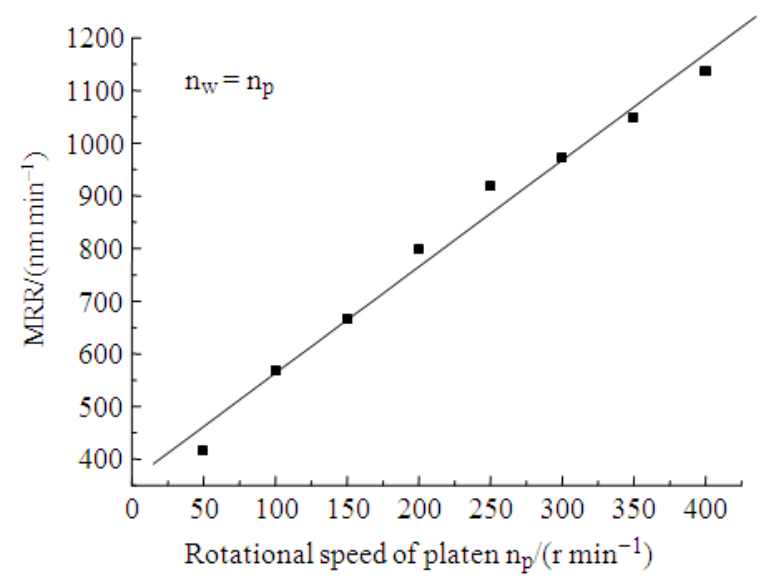

Fig. 5: MRR of CMP using slurry S1

MRR test of wafer CMP: There are 3 deferent slurries, made by Tianjing Jingling Electronic Material Technology Corporation, used in CMP test. One is number S1, the "FA/O" slurry used to polish silicon wafer. The second slurry is number S2 consisting of DI water and abrasives. The content of abrasives in slurry S2 is the same as slurry S1. The third slurry is number $\mathrm{S} 3$. The chemical ingredient and content of Slurry S3 is the same as slurry S1, but without abrasive in it. Test condition is the same as the section of Experimental parameters. In the choice of parameter, take the polishing pressure $\mathrm{P}_{0}=6$ psi. Other parameters are the same as section of Experimental parameters too. The test results are shown in Fig. 4-5. Figure 4 shows the test results polishing with slurry S2 and S3 under different rotational speed. Figure 5 shows the test results polishing with slurry S1 under different rotational speed.
Static corrosive test: The sample was immersed into the slurry S1 for $60 \mathrm{~min}$. During the static corrosive tests, the slurry was stirred continuously. Supposing $M R R_{C}$ denotes the MRR brought by chemical action of slurry. There was $\mathrm{MRR}_{\mathrm{C}}=0.05 \mathrm{~nm} \mathrm{~min}$.

Test of MRR produced by mechanical action of the pad: Supposing $\mathrm{MRR}_{\mathrm{p}}$ denotes the MRR brought by mechanical action of the pad without chemical action. According to the test results of CMP with DI water, the MRR of mechanical action made by polishing pad is $\mathrm{MRR}_{\mathrm{p}}=0.5 \mathrm{~nm} \mathrm{~min}{ }^{-1}$.

\section{DISCUSSION}

Analyzing of MRR produced by mechanical action of the abrasive: By Fig. 4, because there is no chemical ingredient in slurry S2, it can be concluded that the MRR polishing with Slurry S2 is brought by the mechanical action of the pad and the abrasive. By the analysis above-mentioned, the mechanical action of the pad is very small. So it can be considered that the MRR polishing with Slurry S2 is fully brought by the mechanical action of the abrasive. Supposing $M_{R} R_{a m}$, $\mathrm{MRR}_{\mathrm{S} 2}, \mathrm{MRR}_{\mathrm{S} 3}$ denote the MRR produced by mechanical action of abrasive, the MRR polishing with slurry S2 and the MRR polishing with slurry S3, respectively. So, there is $\mathrm{MRR}_{\mathrm{am}}=\mathrm{MRR}_{\mathrm{S} 2}-\mathrm{MRR}_{\mathrm{p}} \approx$ $\mathrm{MRR}_{\mathrm{S} 2}$.

Analyzing of MRR produced by the interaction between the mechanical action of the pad and the chemical action of slurry: By Fig. 4, because there is no abrasive in slurry $\mathrm{S} 3$, it can be concluded that the MRR polishing with Slurry S3 is brought by the mechanical action of the pad, the chemical action and the interaction between the mechanical action of the pad and the chemical action of slurry. According to the analysis above-mentioned, the $\mathrm{MRR}_{\mathrm{C}}=0.05 \mathrm{~nm} \mathrm{~min}$ and the $\mathrm{MRR}_{\mathrm{p}}=0.5 \mathrm{~nm} \mathrm{~min}{ }^{-1}$. So it can be considered that the MRR polishing with Slurry S3 is fully brought by the interaction between the mechanical action of the pad and the chemical action of slurry. So, there is $\mathrm{MRR}_{\mathrm{PC}}=\mathrm{MRR}_{\mathrm{S} 3}-\mathrm{MRR}_{\mathrm{C}}-\mathrm{MRR}_{\mathrm{p}} \approx \mathrm{MRR}_{\mathrm{S} 3}$. Where $M_{R R}$ is the MRR of the interaction between the mechanical action of the pad and the chemical action of slurry.

Analyzing of MRR produced by the interaction between the mechanical action of the abrasive and the chemical action of slurry: Supposing $M R R_{a C}$ is the MRR of the interaction between the mechanical action of the abrasive and the chemical action of slurry. 
According to the analysis above-mentioned, there is $\mathrm{MRR}_{\mathrm{aC}} \approx \mathrm{MRR}_{\mathrm{S} 1}-\mathrm{MRR}_{\mathrm{S} 2}-\mathrm{MRR}_{\mathrm{S} 3}$. Then, the $\mathrm{MRR}_{\mathrm{aC}}$ under different rotational speed can be calculated expediently. supposing that $\mathrm{CR}$ is the contribution rate for the MRR, $C R=M R R_{i} / M R R_{S 1}, M R R_{i}$ is the material removal rate produced by the $i$ factor, $M R R_{a}$ is the material removal rate produced by the abrasive, $M_{R} R_{a}$ $=\mathrm{MRR}_{\mathrm{am}}+\mathrm{MRR}_{\mathrm{aC}}$. So, the interaction between the mechanical action of the abrasive and the chemical action of slurry was in dominant and had a very important influence in MRR in wafer CMP.

According to the analysis results above-mentioned, the mechanical action produced by abrasive on wafer surface is the main mechanical action in material removal of wafer. By abrasion theory, it is concluded that the material removal behavior is two-body abrasive wear under chemical action of slurry mainly in traditional CMP process. However, the two-body abrasive wear can be realized only when the abrasive is embedded the asperity of the pad under the pressure of the wafer and removals the chemical reaction layer on wafer surface. So it is concluded that the contact form between the wafer and the pad is solid-solid contact in wafer CMP process and the polishing pressure is born by the pad fully.

\section{CONCLUSION}

- In wafer CMP process, the contact form between the wafer and the pad can be deduced by the abrasion behavior on wafer surface and the lubrication behavior between the wafer and the pad

- According to the tribological behavior of the wafer CMP system, it can be drawn that the lubrication state of wafer CMP should be in the boundary lubrication, not mixed lubrication, say nothing of hydrodynamic lubrication. The material removal of the wafer surface is the process with the growing and destructing of the boundary film produced by chemical reaction on wafer surface

- The material removal behavior is two-body abrasive wear under chemical action of slurry mainly, the contact form between the wafer and the pad is solid-solid contact in wafer CMP process and the polishing pressure is born by the pad fully

\section{ACKNOWLEDGEMENT}

Supported by the National Natural Science Foundation of China (51075125), the Key Project of Science and Technology R and D Program of Henan Province (102102210405), the key scientific research Program of economic and social development of Xinxiang City (S10004) and Funded by Science and
Technology Innovation Program of Henan Institute of Science and Technology.

\section{REFERENCES}

Abdullah, H., A. Lennie, M.J. Saifuddin and I. Ahmad, 2009. The effect of electrical properties by texturing surface on GaAs solar cell efficiency. Am. J. Eng. Applied Sci., 2: 189-193. DOI: 10.3844/ajeassp.2009.189.193

Ali, A., M. Hosseini and B.B. Sahari, 2010. A review of constitutive models for rubber-like materials. Am. J. Eng. Applied Sci., 3: 232-239. DOI: 10.3844/ajeassp.2010.232.239

Bais, B. and B.Y. Majlis, 2008. Low-g Area-changed MEMS accelerometer using bulk silicon technique. Am. J. Applied Sci., 5: 626-632.

Bozkaya, D. and S. Muftu, 2009. A material removal model for CMP based on the contact mechanics of pad, abrasives and wafer. J. Electrochem. Soc., 156: 890-902. http://dx.doi.org/10.1149/1.3231691

Krishnan, M., J.W. Nalaskowski and L.M. Cook, 2010. Chemical mechanical planarization: Slurry chemistry, materials, and mechanisms. Chem. Rev., 110: 178-204. PMID: 19928828

Liang, H., 2005. Chemical boundary lubrication in chemical-mechanical planarization. Tribol. Int., 38: 235-242. DOI: 10.1016/J.TRIBOINT.2004.08.006

Lin, J.F., J.D. Chen and Y.H. Chang, 2004. Analysis of the tribological mechanism arising in the chemical mechanical polishing of copper-film wafers. J. Tribol., 126: 185-199. DOI: 10.1115/1.1631010

$\mathrm{Ng}$, S.H., C.F. Higgs and I. Yoon, 2005. An analysis of mixed lubrication in chemical mechanical polishing. J. Tribol., 127: 287-292. DOI: 10.1115/1.1760551

Qura'n, F.A., 2007. Analysis of motion of partial system on phase plane and determination of stable cutting regions. Am. J. Applied Sci., 4: 49-52. DOI: 10.3844/ajassp.2007.49.52

$\mathrm{Su}$, J., J. Du and X. Chen, 2008a. Investigation on contact form of interface in silicon wafer CMP based on abrasion behavior. Tribological, 28: 111-116. http://direct.bl.uk/bld/PlaceOrder.do?UIN=231411 196\&ETOC $=$ RN\& from $=$ searchengine

Su, J., X. Chen and X. Zhang, 2008b. Study on characteristic of material removal rate in chemical mechanical polishing of silicon wafer. J. Comput. Theoret. Nanosci., 5: 1656-1660. DOI: 10.1166/jctn.2008.844

Terrell, E.J., R.B. Comes and C.F. Higgs, 2010. Analysis of feature-scale wear in chemical mechanical polishing: Modeling and experiments. Tribol. Lett., 37: 327-336. DOI: 10.1007/s11249009-9524-5 
Yeruva, S.B., C.-W. Park and Y.I. Rabinovich, 2009. Impact of pad-wafer contact area in chemical mechanical polishing. J. Electrochem. Soc., 156: 408-412. http://dx.doi.org/10.1149/1.3186032
Zhao, Y. and L. Chang, 2002. A micro-contact and wear model for chemical-mechanical polishing of silicon wafers. Wear, 252: 220-226. DOI: 10.1016/S0043-1648(01)00871-7 